Journal of

Biomedical Engineering and Research

\title{
Human Osteogenic Adipose-Derived Progenitor Cells as a Source of Vascular Endothelial Growth Factor
}

John D. Murray MD, FACS ${ }^{1}$, Bharani Krishna Mynampati, $\mathrm{PhD}^{2}$, Sarah Fernandez, $\mathrm{MD}^{3}$, Marie Crandall, $\mathrm{MD}$, MPH, FACS ${ }^{4}$, Edward W. Scott, $\mathrm{PhD}^{5}$

${ }^{1}$ The University of Florida at Jacksonville, Division of Plastic Surgery

${ }^{2}$ The University of Florida at Jacksonville, Department of Ophthalmology

${ }^{3}$ The University of Florida at Jacksonville, Division of Plastic Surgery

${ }^{4}$ The University of Florida at Jacksonville, Department of Surgery

${ }^{5}$ The University of Florida at Gainesville, Department of Microbiology and Molecular Genetics

${ }^{*}$ Corresponding author: John Murray, MD, FACS, 653 West $8^{\text {th }}$ Street, Faculty Bldg., $3^{\text {rd }}$ floor, Jacksonville, FL 32209, Tel: 904244-3915, Fax 904-244-3870, E-mail: john.murray@jax.ufl.edu

Received Date: May 23, 2019 Accepted Date: June 15, 2019 Published Date: June 18, 2019

Citation: John D. Murray MD, FACS (2019) Human Osteogenic Adipose-Derived Progenitor Cells as a Source of Vascular Endothelial Growth Factor. J Biomed Eng 1: 1-14.

\section{Introduction}

Cardiovascular disease remains the leading cause of death worldwide, with coronary ischemic heart disease accounting for $80 \%$ of these fatalities [1-3]. With the total costs of cardiovascular disease rising and expecting to reach $\$ 1.1$ trillion in the United States alone by 2035, [4] heart failure is in need of new therapies.

Cell-based therapies have shown particular promise in several difficult-to-treat conditions and diseases [5-7]. Human adipose-derived stem cells (ASCs) hold unique qualities for use in regenerative medicine. A well-known benefit of ASCs lies in their unique ability to differentiate along with several mesodermal and endothelial lineages as human adipose-derived progenitor cells (APCs) [8,9]. APCs may directly repair, replace, or regenerate multiple cell types in the cardiac myocardium [10-13]. In addition to the regenerative benefit of multi-differentiation, ASCs also secrete several cytokines that promote angiogenesis. One of the most well studied angiogenic cytokine is vascular endothelial growth factor (VEGF) $[8,9,14,15]$. VEGF is involved in several angiogenic functions, to include endothelial cell migration, mitogenesis, vascular sprouting, and vascular tube formation $[16,17]$. VEGF-A is the most active multi-tasking factor among the VEGF family of proangiogenic cytokines and is essential for cardiovascular development and function $[18,19]$.

Translational therapy with VEGF-Alone for ischemic heart disease has been an intense focus of research. Intracoronary and intravenous infusions of recombinant VEGF (rVEGF) in patients with coronary disease have been encouraging [20-22]. However, clinical trials with VEGF therapy, either through gene therapy or through infusion, have not demonstrated statistical clinical benefit [23-28]. The short half-life and hypotensive side effects of infused rVEGF-A limit its angiogenic potency [21,29]. In this study, we examine the hypothesis that APC might secrete greater quantities of VEGF-A ${ }_{165}$ than ASCs and therefore may be better potential therapeutic candidates for cardiac repair than ASCs alone. The purpose of this study was to quantitate secreted VEGF-A ${ }_{165}\left(\mathrm{sVEGF}_{-\mathrm{A}_{165}}\right)$ from ASCs and APCs of adipogenic, osteogenic, and chondrogenic lineages and correlate those quantities to a known median effective dose $\left(\mathrm{ED}_{50}\right)$ of $\mathrm{rVEGF}_{165}$ activity.

Keywords: Adipose-derived stem cells, adult stem cells, VEGF, heart disease, progenitor cells

C 2019 The Authors. Published by the JScholar under the terms of the Creative Commons Attribution License http://creativecommons.org/licenses/ by $/ 3.0 /$, which permits unrestricted use, provided the original author and source are credited. 


\section{Abbreviations}

VEGF $=$ vascular endothelial growth factor; rVEGF= recombinant vascular endothelial growth factor; ASCs= adipose-derived stem cells; APCs= adipose-derived progenitor cells; VEGF- $A_{165}=$ vascular endothelial growth factor isoform

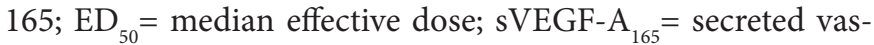
cular endothelial growth factor-A isoform 165; SVF= stromal vascular fraction; HUVECs= human umbilical vein endothelial cells

\section{Methods}

\section{Overview}

Fresh human lipoaspirate underwent enzymatic processing to isolate the stromal vascular fraction (SVF). From the SVF, the ASCs were adherently (plastic) expanded. The ASCs then underwent selected differentiation to produce APCs along osteogenic, adipogenic, and chondrogenic lineages. An undifferentiated ASC control was also cultured concurrently. A sample of the supernatant from each of the four populations was then collected and tested at culture days 7, 14, and 21 for determination of levels of sVEGF-A ${ }_{165}$. Complete media change for all four populations was performed on culture day $4,7,11,14$, and 18 . Confirmatory cytological stains for each lineage was performed on culture day 14. Additionally, the osteogenic APCs also underwent qualitative immunocy to chemistry for VEGF-A ${ }_{165}$. This study was completed with three contiguously executed series of experiments with three separate patient samples. Each patient sample established a respective "cell line." Each cell line was initially split to allow for continued growth beyond differentiation day 14 (at which time lineage-specific stains were used to assess differentiation in the corresponding other split cell line). The study design schema is represented in figure 1 . This is an index qualitatively descriptive study; no statistical analysis was pursued.

\section{Method of SVF isolation}

Fresh human waste lipoaspirate from informed and consented three healthy females were used for this University of Florida Jacksonville Institutional Review Board approved study (IRB\# 201601520). Each of the three lipoaspirate samples was used to prospectively establish a cell line, from initial ASC expansion to differentiation and analysis. The lipoaspirate had been harvested using standard operative tumescent techniques using syringe liposuction. The tumescent solution included normal saline, lidocaine, and epinephrine. Shortly af- ter harvest, the fresh lipoaspirate was then processed using the "Reviticell Kit" (Reviticell, Inc., Jacksonville, FL) with its inherent 10-step process. In brief, shortly after the lipoaspirate was obtained, 70mls of unconcentrated lipoaspirate was measured out and subsequently underwent intersyringe transfer (between two $60 \mathrm{ml}$ syringes provided as part of the Reviticell Kit) for five transfers. Then, $17.5 \mathrm{ml}$ of lipoaspirate was placed into each of four $35 \mathrm{ml}$ custom Transfer Syringes (produced for Reviticell by Cardinal Health, Dublin, $\mathrm{OH}$ and pre-labeled as such by Reviticell). Subsequently, $20 \mathrm{ml}$ of normal saline was added to each syringe and a homogenous suspension was created. The plunger rods were then removed and the four Transfer Syringes were centrifuged for 3 minutes at $340 \mathrm{xg}$ (Drucker Diagnostics, 755VES, State College, PA). The concentrated pellet at the bottom of each of the four Transfer Syringes was then added to a Concentrate Syringe (standard $35 \mathrm{ml}$ syringe pre-labeled as such by Reviticell). After discarding the aqueous infranatant from two of the Transfer Syringes, $7.5 \mathrm{ml}$ of lipoaspirate lowest in the adipose column of each of the two Transfer Syringes was transferred to the Concentrate Syringe. A Corase ${ }^{\circledast}$ Syringe (standard $35 \mathrm{ml}$ syringe pre-labeled as such by Reviticell) then received $10 \mathrm{ml}$ of phosphate buffered saline and Corase ${ }^{\circledast}$.

Aliquots of Corase ${ }^{\circledast}(0.5 \mathrm{ml}$ sterile water with $1 \mathrm{mg}$ of Corase $^{\circledast}$ were prepared preoperatively). Corase is produced by Roche Custom Biotech for Reviticell and is identical to LiberaseMNP-S, which is a blended collagenase meeting current Good Manufacturing Practice guidelines. It is a purified (not crude) blend of three enzymes: collagenase I, collagenase II, and thermolysin. Corase specific activity is $3.8 \mathrm{U} / \mathrm{mg}$ or activity of 19-32 Wunsch Units.

The contents of the Concentrate Syringe were then transferred to the Corase ${ }^{\circledR}$ Syringe (thus containing $15 \mathrm{mls}$ of concentrated lipoaspirate with centrifuged pellets from all four centrifuged Transfer Syringes). The Corase ${ }^{\bowtie}$ Syringe was then placed into an incubating rocking platform shaker (VWR, Radnor, PA) at $37^{\circ} \mathrm{C}$ for 20 minutes at tilt level of " 6 " and tilt speed of “30." Half of the contents of the Corase ${ }^{\varpi}$ Syringe was then transferred to each of two Transfer Syringes. To these syringes, $20 \mathrm{ml}$ of saline (provided as a part of the Reviticell Kit) was added and subsequently centrifuged for 3 minutes. The resultant pellet, also defined as the stromal vascular fraction or SVF, in the bottom of each syringe was then collected and combined for culture. 


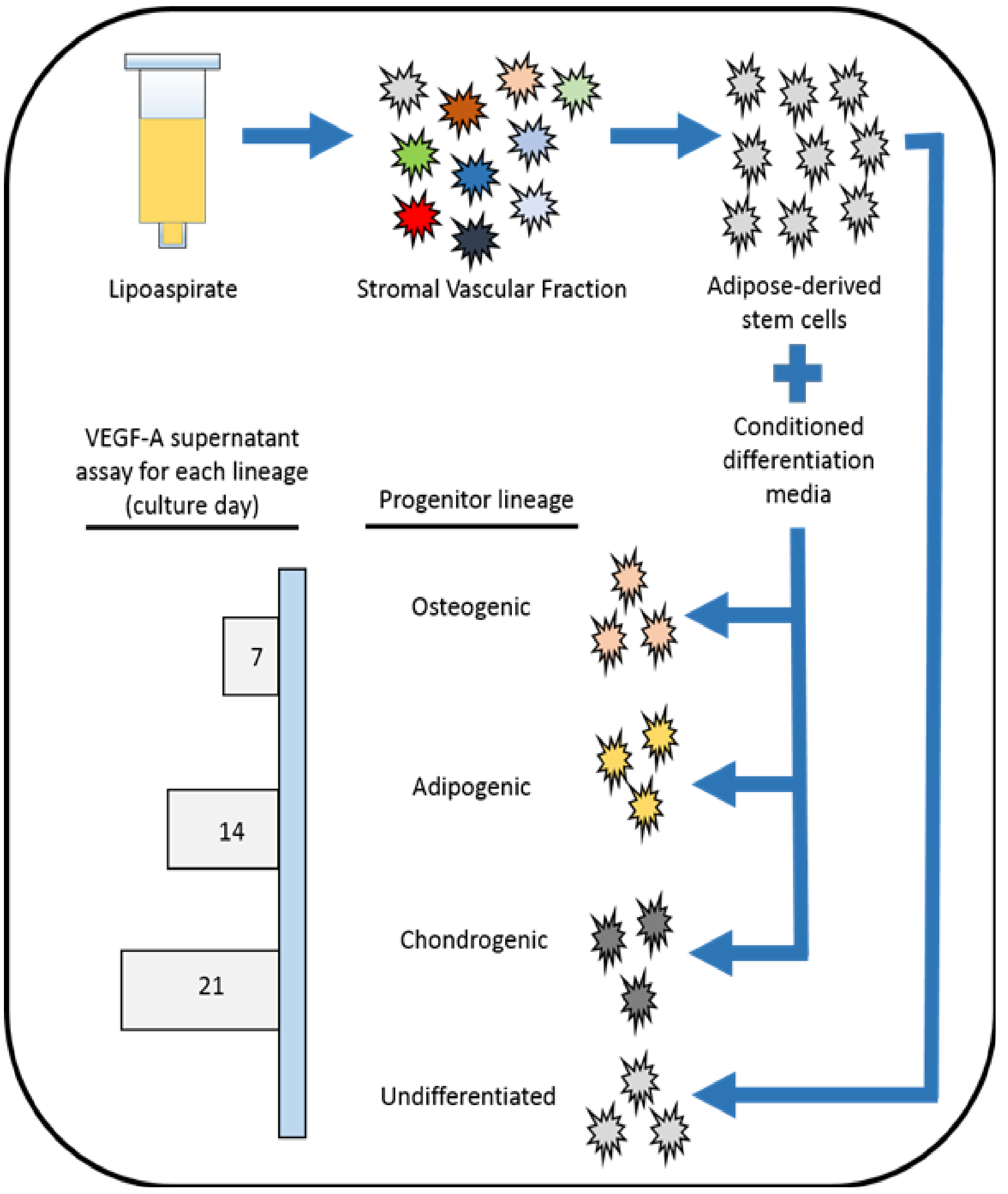

Figure 1: Study design: Beginning with fresh lipoaspirate, SVF was enzymatically isolated and the ASCs were expanded after plastic adherence. The ASCs were then split into three differentiation media for osteogenic, adipogenic, and chondrogenic progenitor development. The supernatant of each lineage was then sampled on culture days 7, 14, and 21 and the sVEGF-A ${ }_{165}$ quantities were determined by immunoassay. Similarly, first passaged undifferentiated ASCs were also expanded and comparatively tested. 
Method of ASC expansion

The SVF was added to 6 MLS of animal component free defined media (MesenCult ${ }^{\mathrm{TN}}$ - ACF basal medium \#05451 and 5X supplement \#05452, STEMCELL Technologies, Vancouver, Canada) in a T-25 culture flask (pre-treated with attachment substrate, STEMCELL Technologies, \#05444. Flask: VWR, Nunclon tissue culture flask \#470174-450) and incubated at humidified $5 \%$ carbon dioxide. Half media change was performed at day 3. The plastic adherent monolayer of ASCs was then expanded for10 days. At this stage, ASCs were harvested for differentiation stimulation, while one aliquot was passaged to a new T-25 culture flask for further expansion without differentiation (media remained the animal component free defined media).

\section{Tri-lineage differentiation}

Expanded cells were dissociated from the culture flask (Mesencult ${ }^{\mathrm{Ts}}$-ACF Dissociation Kit \#05426, STEMCELL Technologies). ASCs were first passaged and seeded on six-well culture plates at approximately 100,000 cells per well (for the osteogenic and adipogenic differentiation and approximately 100,000 cells to the coned tube for the chondrogenic differentiation). After attachment, cells were grown to confluence for the good cultures (the chondrogenic lineage confluence could not be examined due to the coned tube in which the cell resided). Each differentiation population received lineage inducing conditioned media. No cell counts were obtained beyond the initial seeding.

For osteogenic differentiation, basal growth media was exchanged for conditioned osteogenic differentiation medium (STEMCELL Technologies, Mesencult" Osteogenic Stimulatory Kit \#05404). Alizarin Red (Sigma-Aldrich) staining was performed (to specifically stain for calcium) on day 14 and photomicrographs were obtained using whole field bright-light microscopy captured at $15 \mathrm{x}$.

For adipogenic differentiation, basal growth media was exchanged for conditioned adipogenic differentiation medium (STEMCELL Technologies, Mesencult ${ }^{*}$ Adipogenic Differentiation Medium \#05412). Oil red O (Sigma-Aldrich) staining was performed (to specifically stain the lipid droplets) on day 14 and microphotographs were obtained using whole field bright-light microscopy captured at 30x.

For chondrogenic differentiation, basal growth media was exchanged for conditioned chondrogenic differentiation medium (STEMCELL Technologies, Mesencult" Chondrogenic Differentiation Medium \#05455). Culturing took place at the coned bottom of a polypropylene $15 \mathrm{ml}$ tube. Alcian Blue / Nuclear Fast Red (Sigma-Aldrich) staining was performed (to specifically stain sulfated proteoglycans) on day 14 and micrographs were obtained. The micromass sphere was photographed by indirect microscopy.

\section{Secreted VEGF-A ${ }_{165}$ immunoassay}

At days 7, 14, and 21 of culture within the differentiation and non-differentiation media, equal aliquots of media were collected, diluted 1:1 with sterile PBS and immunoassay using luminescence analysis for VEGF using Human Luminex Performance Assay Kit (R\& D Systems, Minneapolis, MN, \#LUH000). This anti-VEGF-A assay detects isoforms of VEGF-A121, 165, and 189 without cross-reactivity for VEGF -B, -C, or -D, according to the manufacturer. Standard cocktails $1 \& 2$ were reconstituted in RD6-40 and serially diluted, per the manufacturer's instructions. A 96-well microtiter plate was used and $100 \mu \mathrm{L}$ of wash buffer was added to pre-wet the plate, $50 \mu \mathrm{L}$ of microparticle bead mixture and $50 \mu \mathrm{L}$ of standard or samples were added and incubated at room temperature for 3 hours on a horizontal orbital microplate shaker $(0.12$ " orbit $)$ set at $500 \pm 50 \mathrm{rpm}$. After incubation, the liquid was removed and wells were washed $3 \mathrm{X}$ with buffer $(100 \mu \mathrm{L})$. Then, $50 \mu \mathrm{L}$ of diluted Biotin Antibody Cocktail was added to each well and incubated for 1 hour at room temperature on the shaker and washed $3 \mathrm{X}$ with buffer. Next, $50 \mu \mathrm{L}$ of diluted Streptavidin-PE was added to each well and incubated for 30 minutes at room temperature before each well was washed $3 \mathrm{X}$ with buffer $(100 \mu \mathrm{L})$. After resuspending the microparticles in $100 \mu \mathrm{L}$ of a buffer, the plates were incubated for 2 minutes and read on a Luminex 100 IS flour analyzer (Luminex, Inc., Northbrook, IL). A known concentration of human recombinant VEGF was included in each run as a positive control and the concentration of unknown samples was calculated from a five-parameter logistic (5-PL) curve-fit using a standard Sigma plot. Media only serves as a control for all test samples and wash buffer alone serves as blank for the experiment. A standard curve for analytes was generated using Sigma plot software capable of generating five parameters (5-PL) logistic curve. VEGF levels were expressed as $\mathrm{pg} / \mathrm{ml}$.

\section{Secreted VEGF- $A_{165}$ osteogenic APC immuno- cytochemistry}

On culture day 21, osteogenic APCs underwent qualitative immunocytochemistry for the presence of VEGF-A ${ }_{165}$. The Thermo Scientific Ultravision Detection System (catalog \# TR-015-HD) was used to conjugate a primary VEGF antibody (Thermo Scientific RB-9031-R7-A) through streptavidin-biotin 
immune-enzyme detection with resultant chromogenic 3,3'diaminobenzidine (DAB) expression for microscopy. According to the manufacturer, the primary VEGF antibody reacts with the 165,189 , and 121 amino acid splice variants of the human VEGF with expected staining of the cytoplasm, cell surface, and extracellular surface. Specimen processing proceeded according to the respective Instructions For Use except that the APCs remained in culture and were not formalin fixed.

\section{Results}

After expansion for 10 days in vitro(see figure 2), ASCs were passaged and underwent progenitor stimulation (osteogenic, adipogenic, and chondrogenic). Similarly, the osteogenic and adipogenic lineages grew to $80 \%$ confluence at day 10 and with complete confluence at about day 14. All progressed to representative phenotypic functional mature differentiation, as positively stained on differentiation culture day 14 (see figure 3 ).

By culture day 21, the osteogenic APCs had developed spheroids. The staining with only Alizarin Red (indicating the presence of calcium) remains diagnostic of osteogenic progenitor cells. As seen in Figure 4, the Alizarin Red staining maintained a light red color. As seen in Figure 5, the staining with only DAB (indicating the presence of VEGF- $\mathrm{A}_{165}$ ) maintains a medium to dark brown color. As seen in Figure 6, staining for both calcium (with Alizarin Red) and VEGF-A ${ }_{165}$-DAB produces a generally lighter red-brown comparative to $\mathrm{DAB}$ alone or darker than Alizarin Red. This observation is phenotypically diagnostic of an osteogenic progenitor sphere producing VEGF- $\mathrm{A}_{165}$.

By an average of the three cell lines, the osteogenic progenitor population produced comparatively the greatest quantity of VEGF- $\mathrm{A}_{165}$, maximally on day 14 at $1,684.73 \mathrm{pg} / \mathrm{ml}$. The chondrogenic lineage consistently produced VEGF- $\mathrm{A}_{165}$, albeit in considerably fewer quantities. The greatest increase in VEGF- $\mathrm{A}_{165}$ production was between days 7 and 14: 186\% increase of VEGF- $A_{165}$ within the osteogenic progenitor lineage. (see Figure $7)$. As this study quantitated secreted VEGF- $A_{165}$ longitudinally among three separate cell lines as harvested from three different patients, each cell line produced comparatively different quantities of VEGF-A ${ }_{165}$ (see Figure 8). However, secreted quantities of $\mathrm{VEGF} \mathrm{A}_{165}$ trended similarly within each cell line.

Calculating VEGF-A ${ }_{165}$ per million cells was based on an average of 650,000 cells per $9 \mathrm{~cm}^{2}$ well. As the media volume within each well at each point of supernatant sampling was $2 \mathrm{ml}$, peak VEGF-A ${ }_{165}$ levels were $5.18 \mathrm{ng} /$ million cells for osteogenic APCs (sampled at day 14), $4.69 \mathrm{ng} /$ million cells for adipogenic
APCs (sampled at day 14), 4.23ng/ million cells for undifferentiated APCs (sampled at day 21), and $1.26 \mathrm{ng} /$ millions cells for chondrogenic APCs (sampled at day 14). See Figure 9.

Current Good Manufacturing Grade rVEGF-A ${ }_{165}$ (Cat\# 293GMP, R\&D Systems, Minneapolis, MN) stimulates proliferation of human umbilical vein endothelial cells (HUVECs). The $\mathrm{ED}_{50}$ (median effective dose) for this standard effect is $1 \mathrm{ng} / \mathrm{mL}$ with a specific activity of approximately $1.7 \times 10^{3} \mathrm{U} / \mu \mathrm{g}$. In the current study, $1.685 \mathrm{ng} / \mathrm{mL}(1,685 \mathrm{pg} / \mathrm{mL})$ was maximally elaborated as sampled, or $3.37 \mathrm{ng}$ total for 650,000 osteogenic cells (2ml/well of 650,000 cells). Osteogenic APCs would achieve $\mathrm{ED}_{50}$ for HUVEC stimulation of $1 \mathrm{ng} / \mathrm{ml}$ at $1.93 \times 10^{5}$ cells (sampled at day 14), $2.13 \times 10^{5}$ cells for adipogenic APCs (sampled at day 14), $2.36 \times 10^{5}$ cells for undifferentiated ASCs (sampled at day 21), and $7.92 \times 10^{5}$ cells for chondrogenic APCs(sampled at day 14). See Figure 10. Additionally, based on comparative VEGF-A ${ }_{165}$ activity of osteogenic APCS, one would need $9.4 \%$ more adipogenic APCs, 18.2\% more undifferentiated ASCs, or $75.6 \%$ more chondrogenic APCs to generate the same level of enzymatic activity of osteogenic APCs.

\section{Discussion}

ARCserve an essential role in cardiac cell and tissue regeneration by offering both structural and hormonal regenerative capabilities. From a structural perspective, ASCs exist in an undifferentiated state, with the ability to self-renew and differentiate along several mesodermal APC lineages[8,9,30-35]. Additionally, animal studies have shown that ASCs have the potential to differentiate in vivo into endothelial cells and cardiomyocytes [34,36,37]. While the maintenance and production of vessels rely on several growth factors and cytokines, VEGF is one of the most critical and well-studied angiogenic growth factors [38]. Hormonally, ASCs have been shown to improve blood flow in a mouse model of hind limb ischemia by secreting angiogenic growth factors, including VEGF [39].

While it appears counterintuitive to deliver osteogenic APCs to adult cardiac tissues damaged by ischemia, it is noteworthy to mention that bone morphogenetic proteins play a well-established role in both vascular growth [40] and cardiac development [41]. Heterotopic bone formation is also a consistent finding in valvular heart disease [42]. Up-regulating angiogenesis and down-regulating bone formation in the therapeutic use of osteogenic APCs for cardiovascular disease will be critical. The current study demonstrates that APCs secreted levels of VEGF- $A_{165}$ in a lineage-dependent manner and osteogenic APCs 


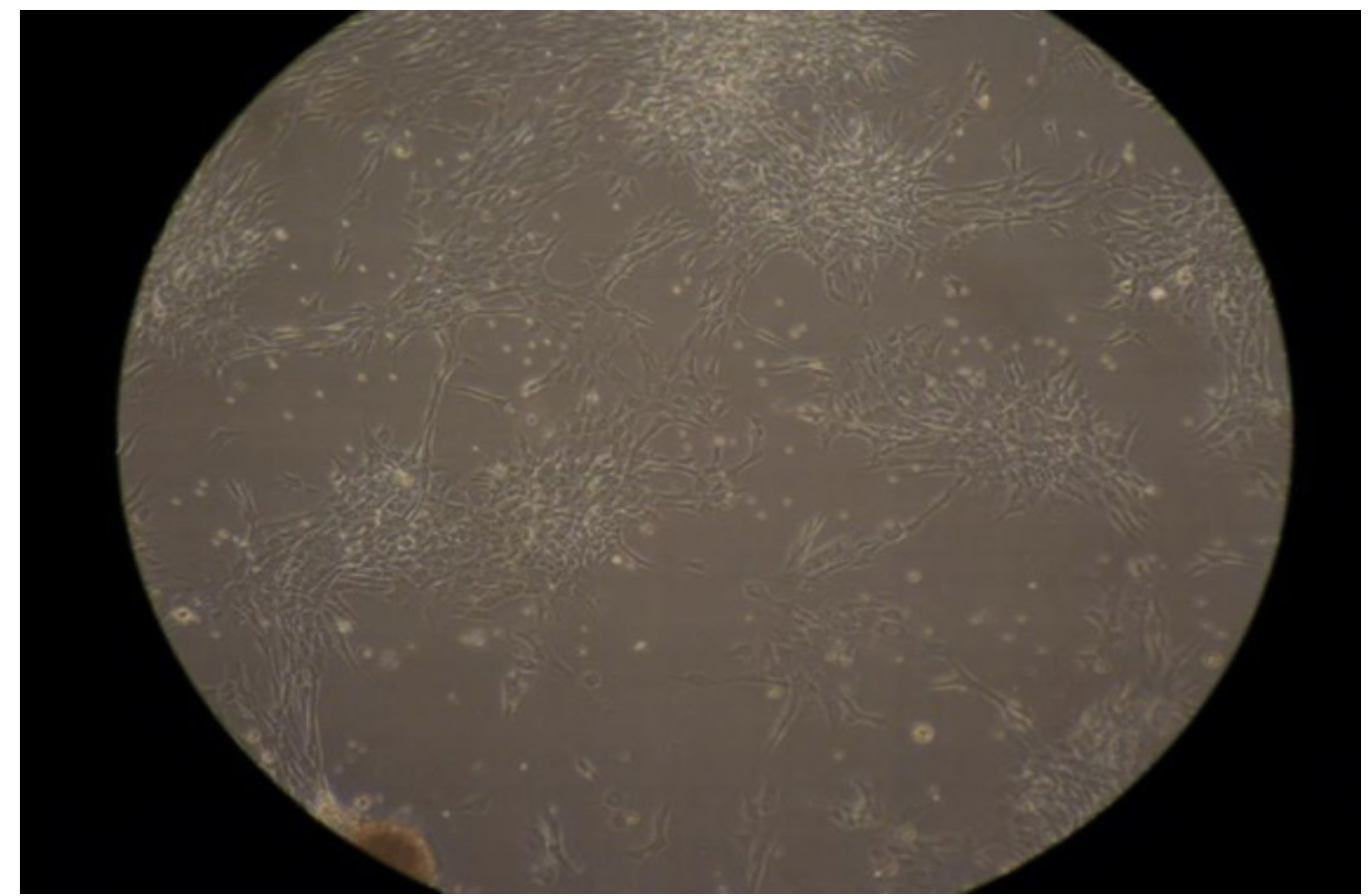

Figure 2. Undifferentiated adipose-derived stem cells.

Representative bright-field 10x micrograph illustrating plastic plate adherence and outward extension of non-passaged adipose-derived stem cells (undifferentiated growth day 10).
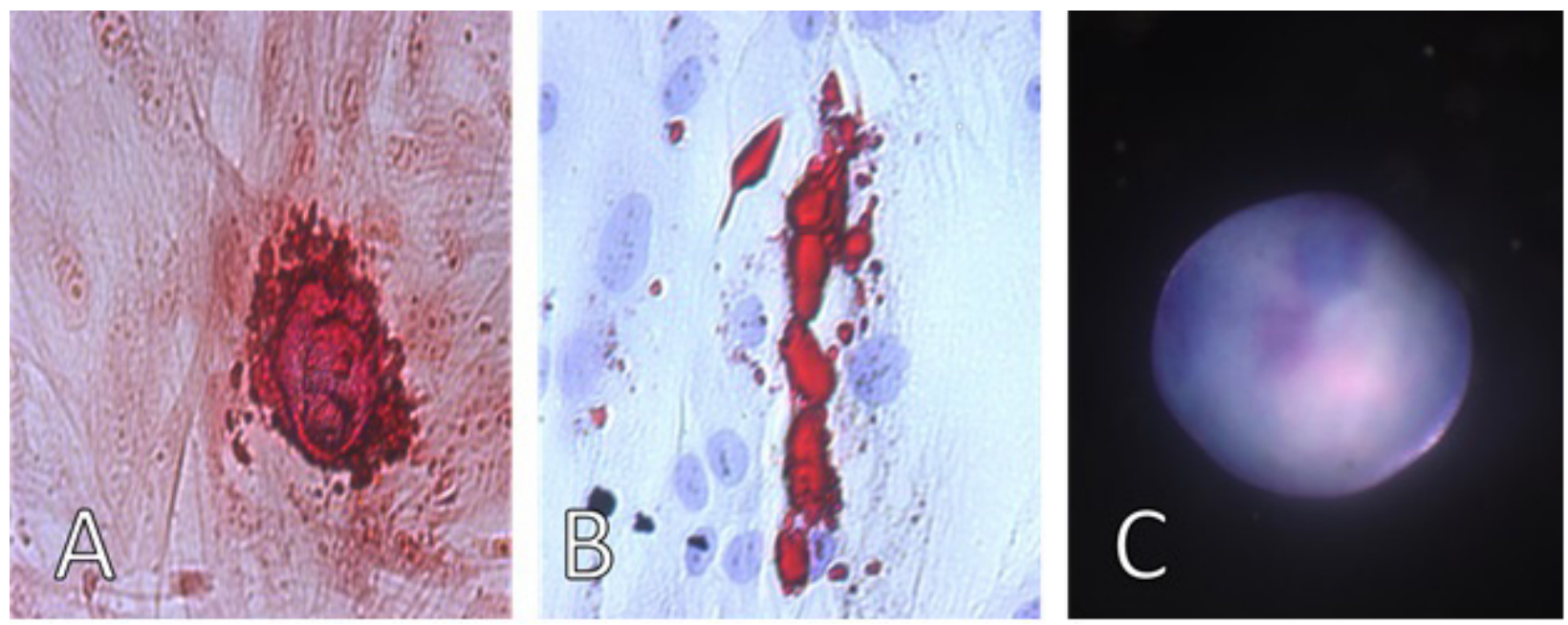

Figure 3. Adult progenitor cells, differentiation day 14. (A) Representative bright-field 15x micrograph illustrating calcium staining by Alizarin Red of adipose-derived stem cells differentiated to osteoblasts. (B) Representative bright-field 30x micrograph illustrating lipid droplet staining of adipose-derived stem cells differentiated to adipocytes. (C) Representative indirect micrograph illustrating a sulfated proteoglycan sphere stained with alcian blue \& nuclear fast red indicating adipose-derived stem cells differentiated to chondroblasts. Sphere diameter $2 \mathrm{~mm}$. 


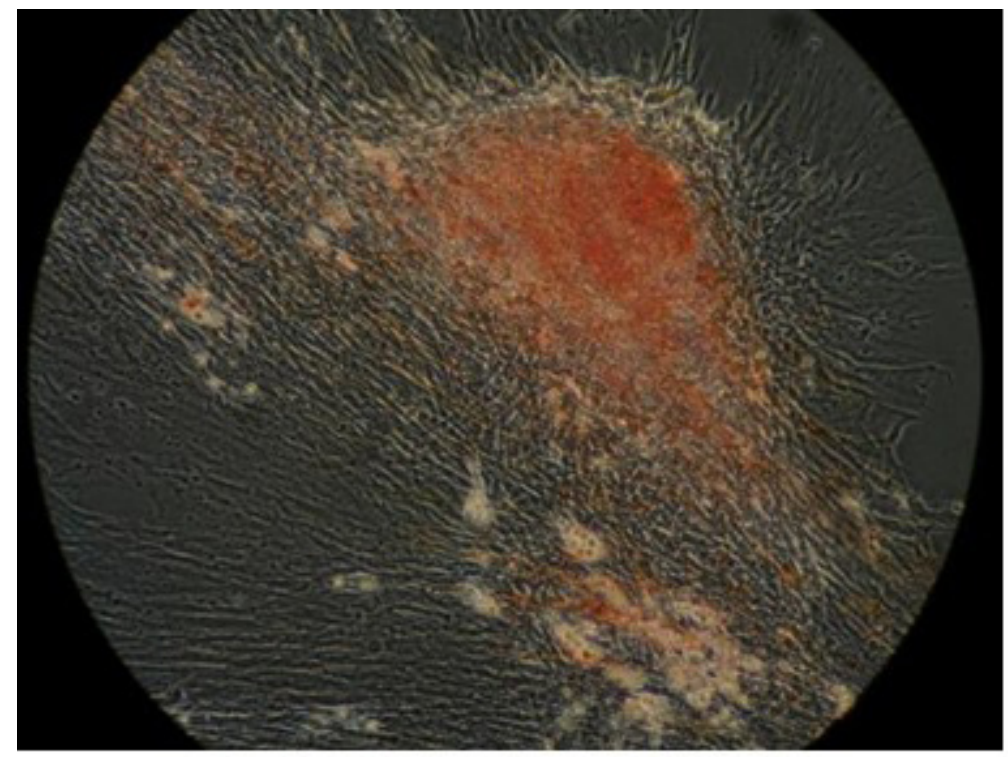

Figure 4. Osteogenic progenitor cell colony

Alizarin Red staining alone for calcium confirms a functional osteogenic progenitor cell colony (40x magnification).
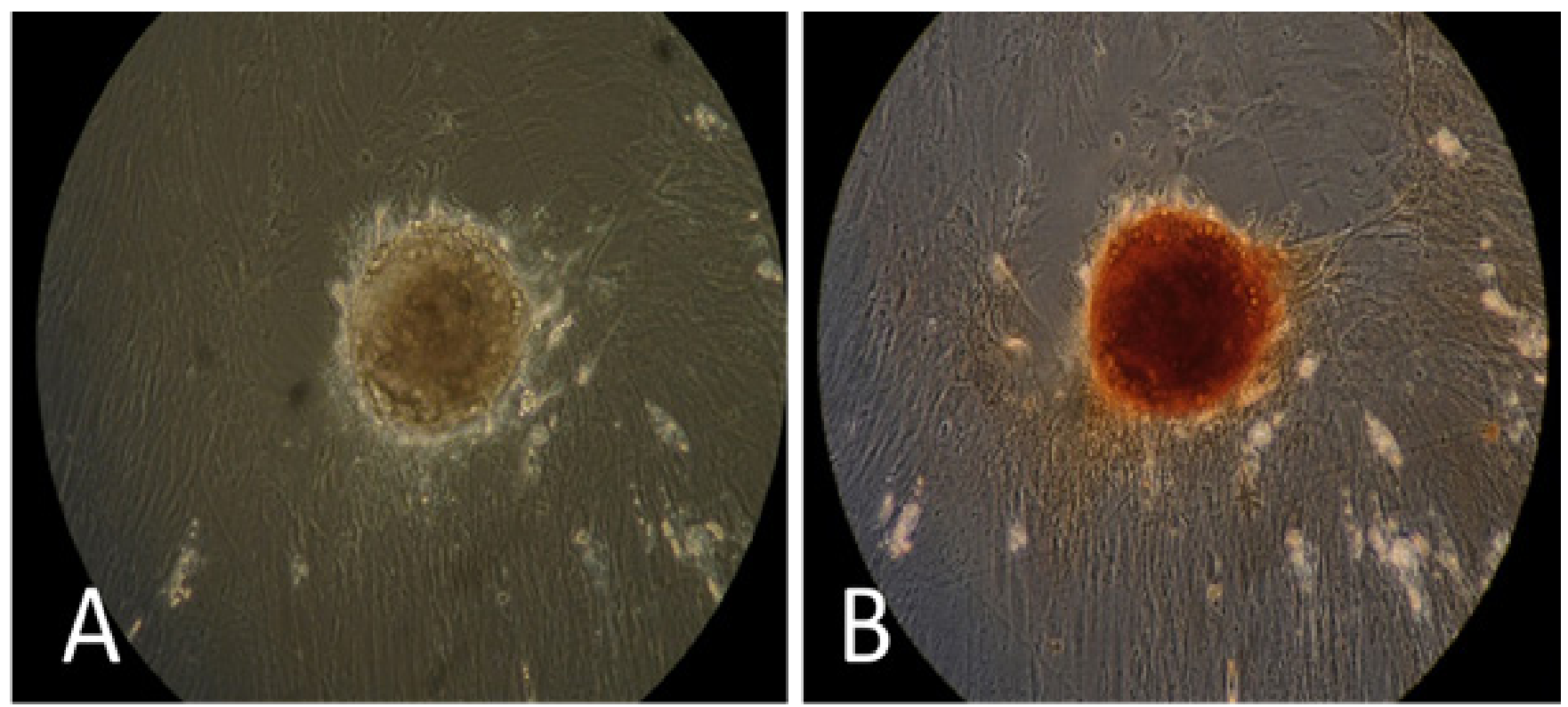

Figure 5. Osteogenic progenitor sphere stained for vegf- $\mathrm{a}_{165^{*}}$.

(A) Presumed osteogenic progenitor sphere (ASCs treated with osteogenic differentiation media), unstained, 20x mag. (B) Same presumed osteogenic progenitor sphere positively stained with DAB (dark brown) alone, indicating the production of VEGF-A ${ }_{165}, 20 \mathrm{x}$ mag. 


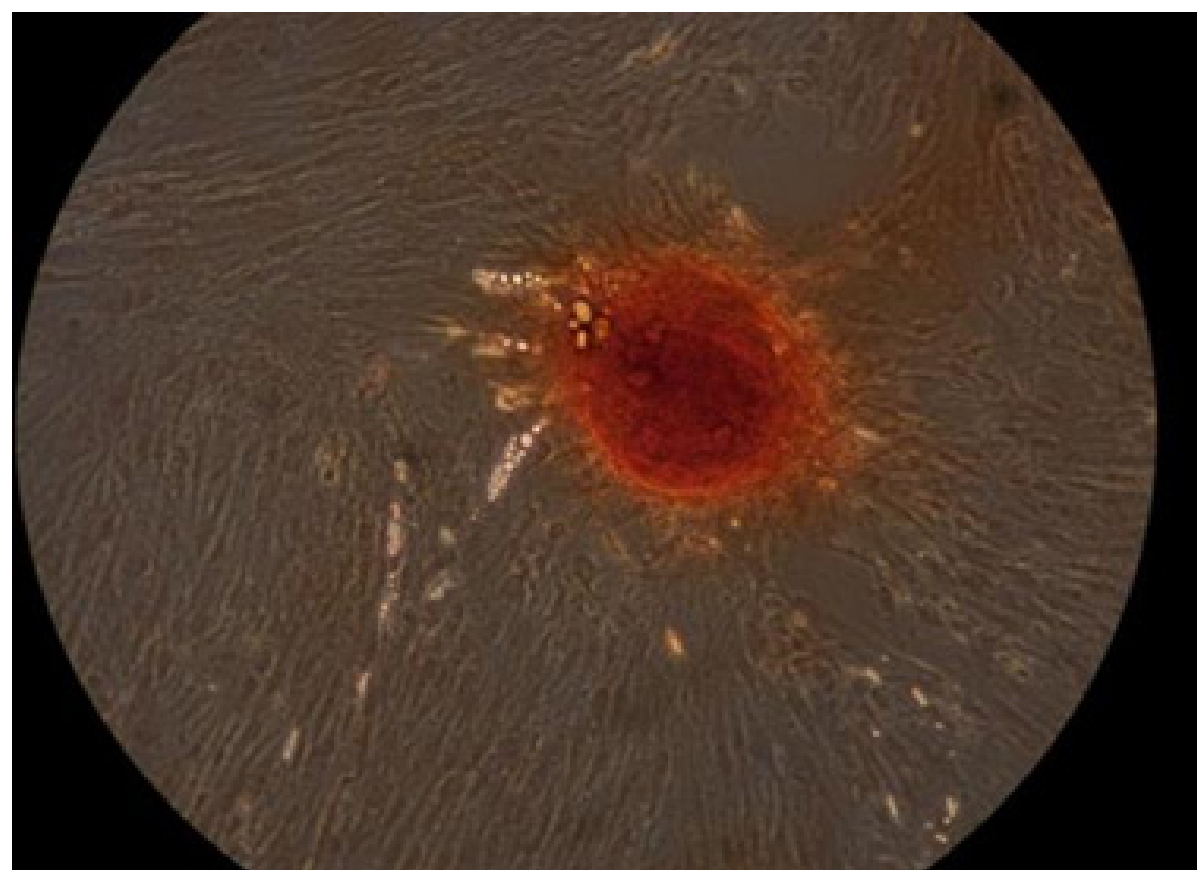

Figure 6. Osteogenic progenitor cell sphere, stained with alizarin red and dab.

This osteogenic progenitor sphere has been stained with Alizarin Red (for calcium) and DAB (for VEGF- $\mathrm{A}_{165}$ ), 20x mag. The staining is comparatively lighter than with $\mathrm{DAB}$ alone and darker than Alizarin Red alone, diagnostic for an osteogenic progenitor sphere producing VEGF- $\mathrm{A}_{165}$.

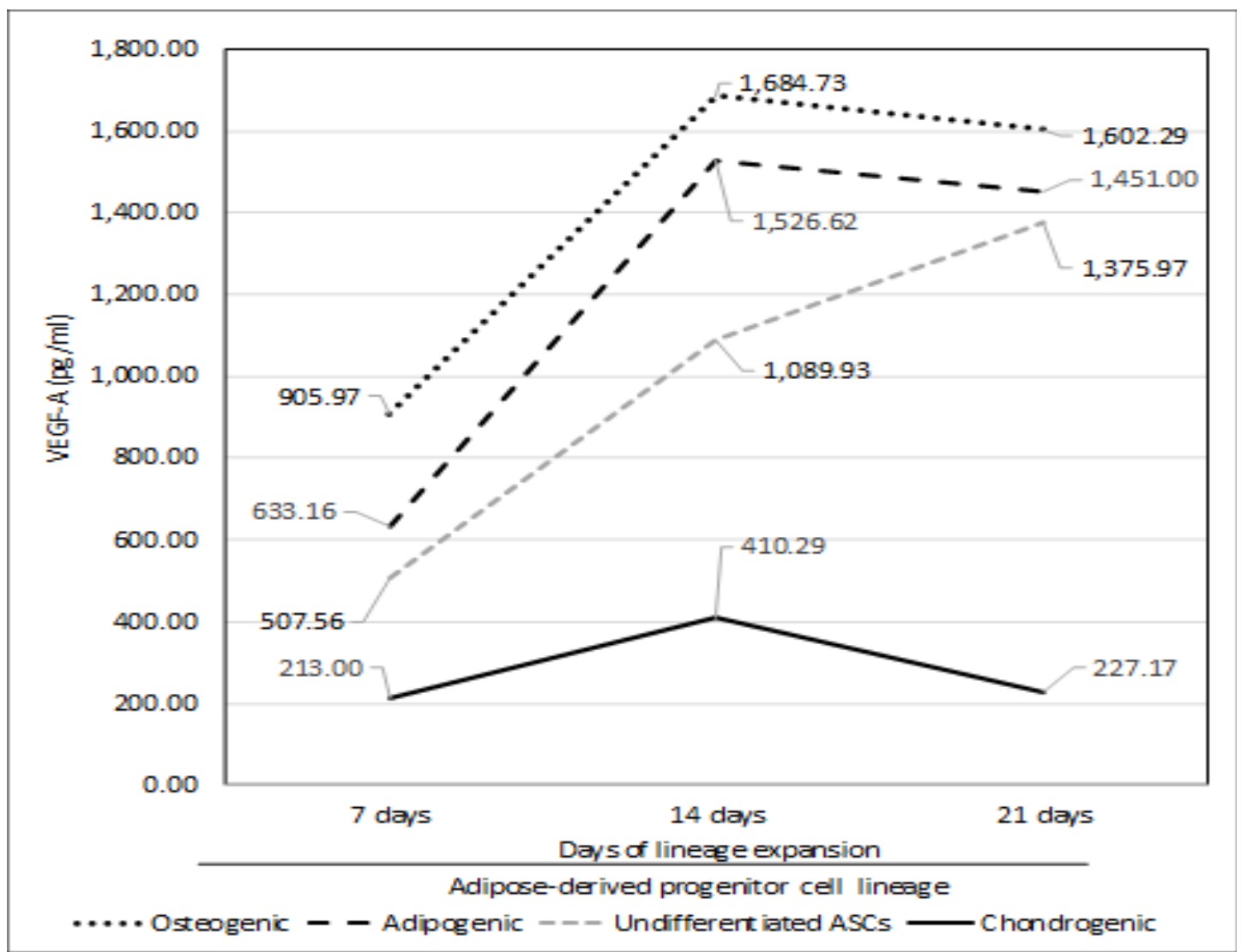

Figure 7. Secreted Vegf- $\mathrm{A}_{165}$ Levels (means of the three cell lines respectively).

At days 7, 14, and 21 of lineage-specific culture, samples of each APC supernatant (osteogenic, adipogenic, and chondrogenic) were obtained and VEGF-A ${ }_{165}$ levels determined by immunoassay. Similarly, the VEGF-A 165 levels of undifferentiated first passaged ASCs were also measured. The osteogenic media displayed the highest levels of VEGF- $\mathrm{A}_{165}$. The chondrogenic lineage secreted the least amount of VEGF-A ${ }_{165}$. 

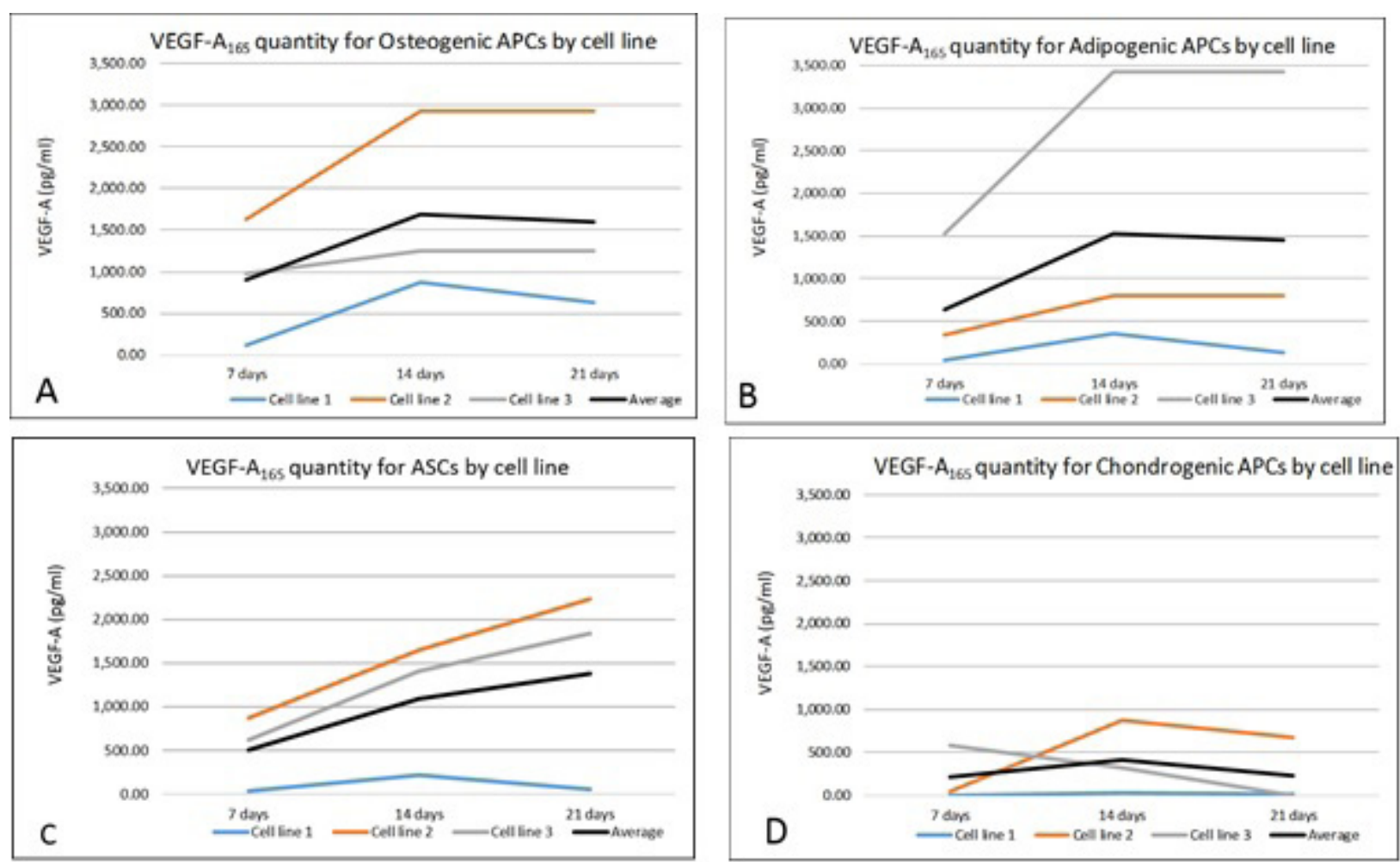

Figure 8. Secreted Vegf- $A_{165}$ Levels (by cell line)

Each of the three cell lines produced respectively different quantities of VEGF- $\mathrm{A}_{165}$, through respective levels trended similarly: panel A (osteogenic APCs), panel B (adipogenic APCs), panel C (ASCs), panel D (chondrogenic APCs).

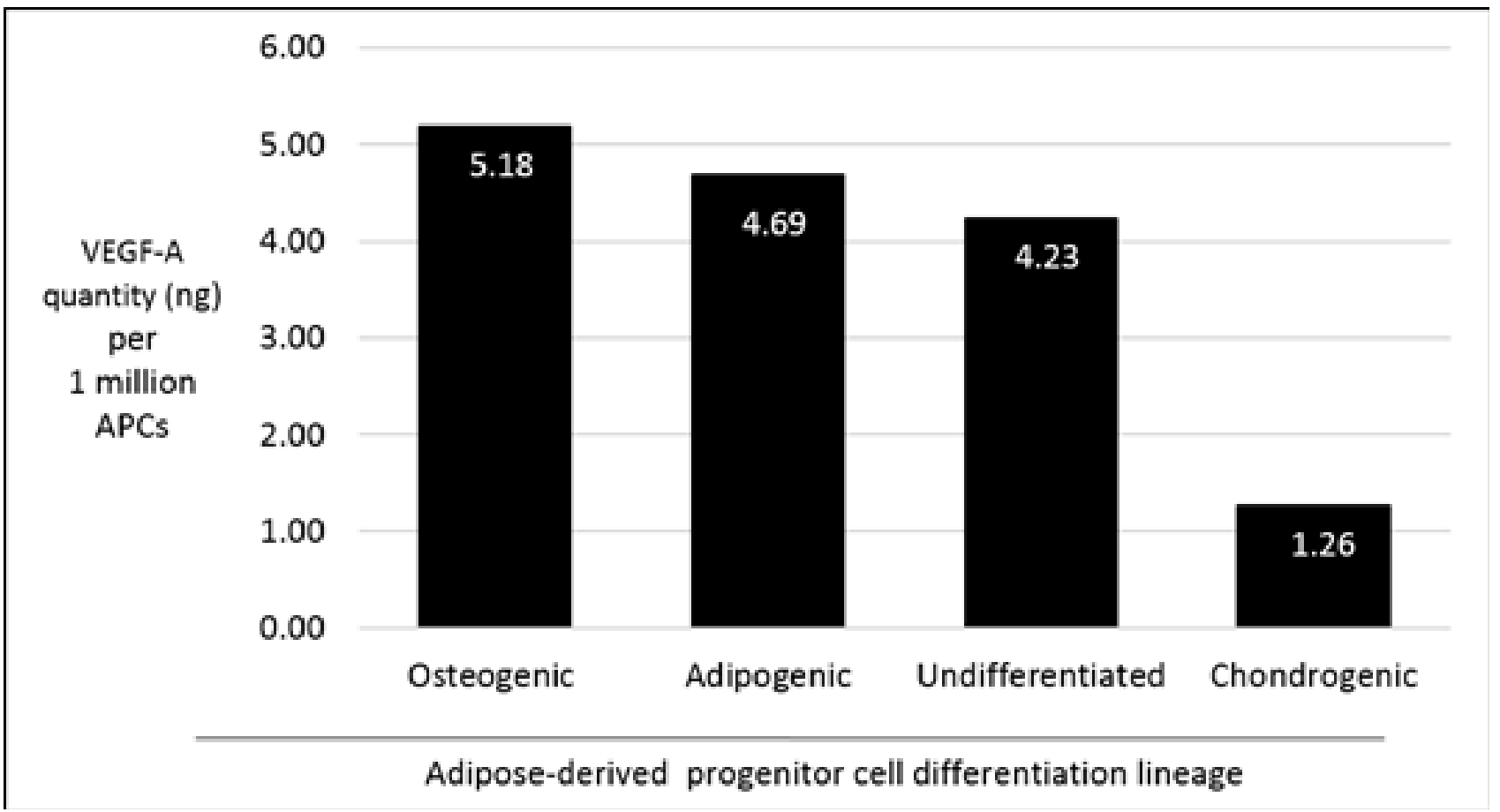

Figure 9. Secreted vegf- $\mathrm{a}_{165}$ maximum levels per $10^{6}$ adipose-derived progenitor cells.

These values are reflective the maximal quantity of VEGF- $A_{165}$ as sampled on differentiation day 14(osteogenic, adipogenic, and chondrogenic APCs) and culture day 21 for undifferentiated ASCs. 


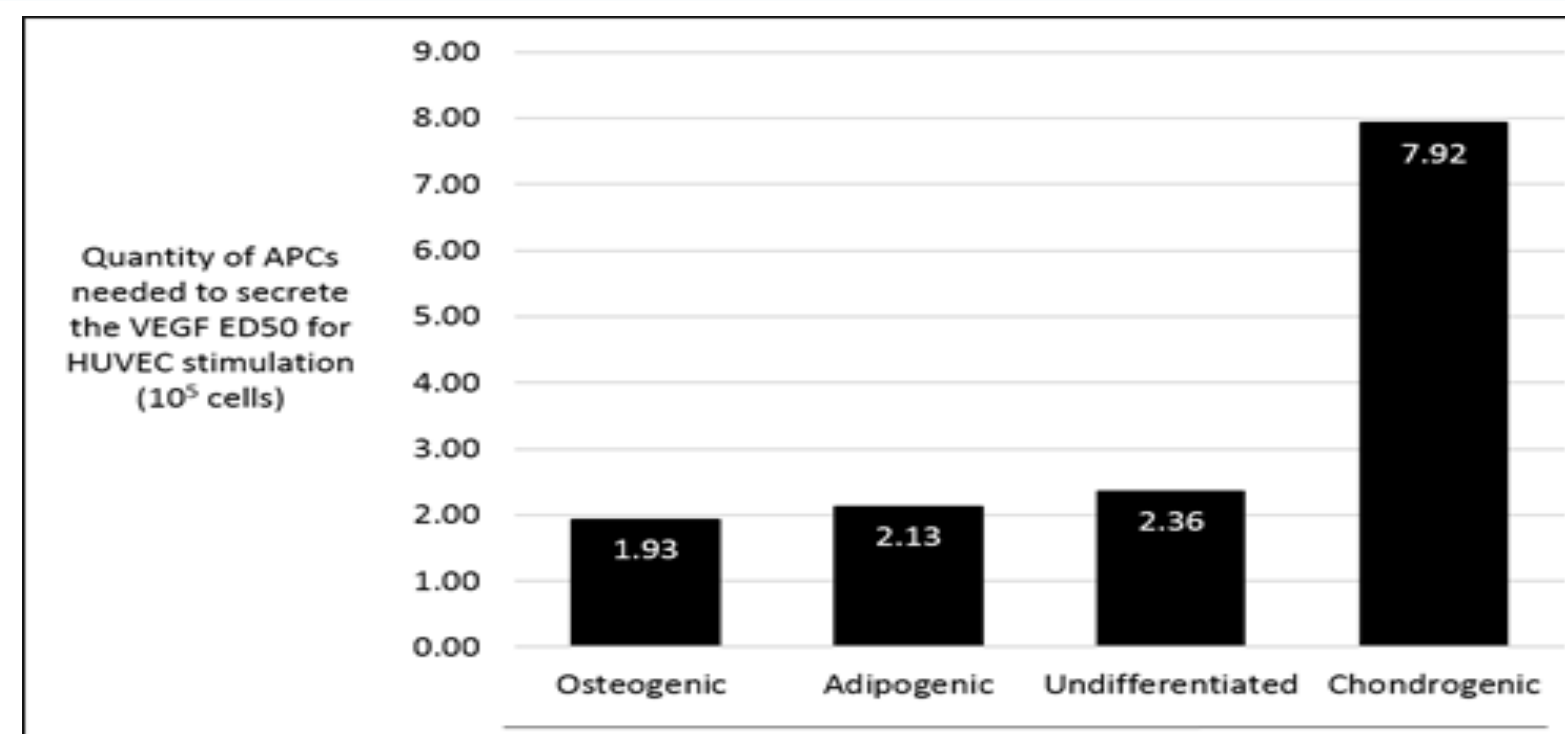

Adipose-derived progenitor cell differentiation lineage

Figure 10. Comparative quantities of apcs to achieve vegf- $\mathrm{a}_{165} \mathrm{ed}_{50}$ for human Umbilical vein endothelial cell (huvec) stimulation. Correlation is specific to Current Good Manufacturing Practice recombinant VEGF-A ${ }_{165}$ (Cat\# 293GMP, R\&D Systems, Minneapolis, MN) and secreted VEGF-A165 levels are reflective of maximum sampling lots (day 14 for APCs and day 21 for undifferentiated ACSs).

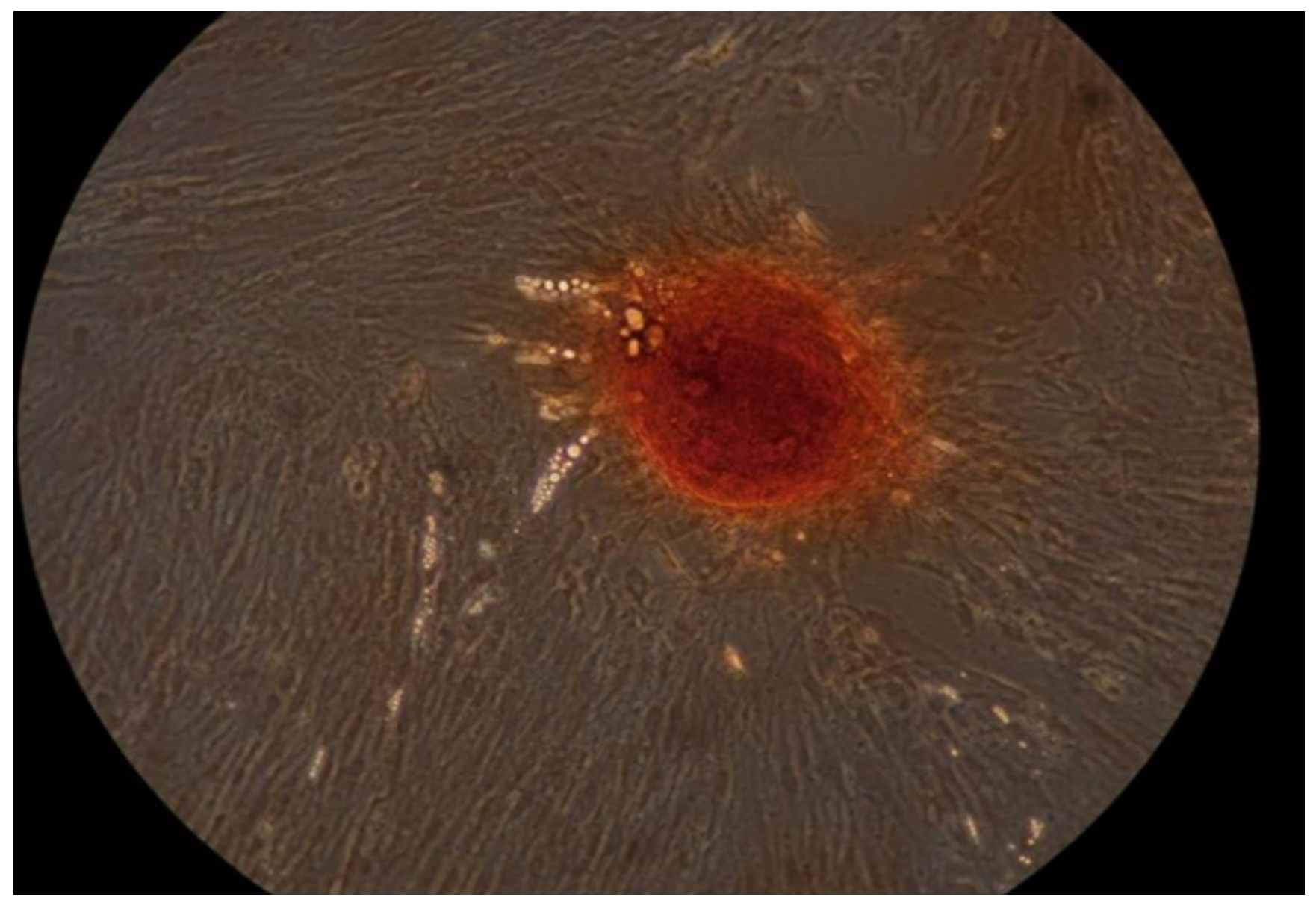

Central Illustration: In this photomicrograph, this osteogenic progenitor cell sphere has been stained for both calcium (confirming osteogenic function) as well as VEGF, confirming that the osteogenic progenitor cells are indeed producing both calcium and VEGF. 
secreted greater quantities of VEGF- $\mathrm{A}_{165}$ than either adipogenic or chondrogenic APCs. This pattern of VEGF in vitro secretion may reflect the dual hematopoietic and structural properties of bone. VEGF-A is a key regulator of perichondrial angiogenesis and osteoblast survival $[43,44]$ but, not osteoblast differentiation[45]. The latter finding suggests that enhanced VEGF-A secretion is not a sufficient determinant of bone formation by osteogenic APCs. In this current study, it may be intuitive to assume that a homogenous population of ASCs treated with an osteogenic differentiation medium may become VEGF- $\mathrm{A}_{165}$ secreting osteogenic progenitor cells; indeed, the VEGF- $\mathrm{A}_{165}-\mathrm{DAB}$ immunostain in combination with the calcium-Alizarin Red stain proved this assumption correct.

The potency of APCs with respect to VEGF-A production may be compared to the known enzymatic activity of $\mathrm{rVEGF}_{165}$. The cell proliferation assay against which rVEGF activity is measured includes HUVEC stimulation [46] The median effective dose $\left(\mathrm{ED}_{50}\right)$ for this effect of Current Good Manufacturing Grade quality rVEGFis 1-6 ng/mL with a specific activity of approximately $1.7 \times 10^{3} \mathrm{U} / \mu \mathrm{g}$ (Cat\# 293GMP, R\&D Systems, Minneapolis, $\mathrm{MN}$ ). As a comparative measure, $1.93 \times 10^{5}$ osteogenic APCs would be needed to achieve an $\mathrm{ED}_{50}$ for HUVEC stimulation based on known activity of $\mathrm{rVEGF}_{165}$. In vivo modeling for the efficacy of cardiac performance of with secreted VEGF- $A_{165}$, as elaborated by infused ASCs, will need to be compared against rVEGF-A ${ }_{165}$ infusion in a head-to-head study.

Therapeutic in vivo tissue regeneration will require the classical components that ex vivo tissue engineering requires: matrix scaffolds, cells, and signaling molecules. However, a stark difference between in vivo and ex vivo tissue engineering will be the inherent more complex dynamics between these three entities as appreciated vivo. While the complete characterization of ASCs, much fewer APCs, is currently unknown, designing regenerative therapies that will leverage the original biological characteristics of these therapeutic cells will be mandatory. As can be seen from the three cell lines, each cell line produced differing quantities of VEGF- $A_{165}$ though each cell line was cultured in ostensibly same culture conditions. A limitation of this study is the small sample size (three cell lines) and certainly, further studies instituting a greater cell line quantity will be needed to better assess these current findings. Finally, while speculative, including ASCs as cellular constituents to the tissue-building process, may afford unintended benefits; for example, they may differ to fibroblasts to produce matrix proteins (such as collagen), they may differentiate to cells to stabilize the micro-milieu (such as in their anti-inflammatory abilities), and they may differ to cells to produce signaling cytokines (such as VEGF). However, what is not speculative is that we cannot live without them. Matching their original biological characteristics to targeted therapies will be essential in establishing much-needed healthcare solutions.

\section{Conclusions}

Culture-expanded osteogenic APCssecreteVEGF-A ${ }_{165}$ in greater quantities than adipogenic and chondrogenic APCs or from undifferentiated ASCs. Osteogenic APCs secrete the $\mathrm{ED}_{50}$ of a Current Good Manufacturing Grade rVEGF at culture day 14, with 193,000 cells needed respectively. By secreting clinically useful quantities of VEGF-A ${ }_{165}$, osteogenic APCs may be a cellbased option for the treatment of ischemic diseases.

\section{Tweet}

Human osteogenic adipose-derived progenitor cells as a source of vascular endothelial growth factor for the treatment of cardiovascular disease

\section{Disclosure of potential conflicts of interest}

J.D.M. is a founder, Board Member, and owns equity in Reviticell Holdings, Inc., a private company which developed the Reviticell Kit described in this research. The company did not have oversight over study design, results, or publication. J.D.M. did not solicit nor consent patients, nor collect data for this study. No other authors have a conflict to disclose.

\section{Acknowledgments}

We wish to thank Dr. Robert Cafferata for his sage insight and wisdom as well as his tireless efforts that helped to make this research possible. 


\section{References}

1. (2018) World Health Organization. Cardiovascular diseases, fact sheet 2017. Updated 2017.

2. (2018) National Heart, Lung, and Blood Institute. Coronary heart disease.

3. Lloyd-Jones DM, Hong Y, Labarthe D, et al. (2010) Defining and setting national goals for cardiovascular health promotion and disease reduction: The American heart association's strategic impact goal through 2020 and beyond. Circulation. 121:586613.

4. Benjamin EJ, Virani SS, Callaway CW, et al. (2018) Heart disease and stroke statistics-2018 update: A report from the American heart association. Circulation.

5. Bender E (2016) Cell-based therapy: Cells on trial. Nature 540: 106-108.

6. Buzhor E, Leshansky L, Blumenthal J, et al. (2014) Cell-based therapy approaches The hope for incurable diseases. Regen Med 9:649-672.

7. Kalladka D, Sinden J, Pollock K, et al. (2016) Human neural stem cells in patients with chronic ischaemic stroke (PISCES): A phase 1, first-in-man study. Lancet. 388:787-796.

8. Zuk PA, Zhu M, Mizuno H, et al. (2001) Multilineage cells from human adipose tissue: Implications for cell-based therapies. Tissue Eng 7:211-228.

9. Zuk PA, Zhu M, Ashjian P, et al. (2002) Human adipose tissue is a source of multipotent stem cells. Mol Biol Cell 13:4279-4295.

10. Sussman MA, Murry CE (2008) Bones of contention: Marrow-derived cells in myocardial regeneration. J Mol Cell Cardiol 44:950-953.

11. Thakker R, Yang P (2014) Mesenchymal stem cell therapy for cardiac repair. Curr Treat Options Cardiovasc Med 16:323.

12. Rehman J, Traktuev D, Li J, et al. (2014) Secretion of angiogenic and antiapoptotic factors by human adipose stromal cells. Circulation 109:1292-1298.
13. Kapur SK, Katz AJ (2013) Review of the adipose derived stem cell secretome. Biochimie 95:2222-2228.

14. Brown JC, Shang H, Li Y, Yang N, Patel N, Katz AJ (2017) Isolation of adipose-derived stromal vascular fraction cells using a novel point-of-care device: Cell characterization and review of the literature. Tissue Eng Part C Methods. 23:125-135.

15. Harper SJ, Bates DO (2008) VEGF-A splicing: The key to anti-angiogenic therapeutics? Nat Rev Cancer 8:880-887.

16. Ucuzian AA, Gassman AA, East AT, Greisler HP (2010) Molecular mediators of angiogenesis. J Burn Care Res. 31:158-175.

17. Fearnley GW, Smith GA, Harrison MA, Wheatcroft SB, Tomlinson DC, Ponnambalam S (2013) Vascular endothelial growth factor-A regulation of blood vessel sprouting in health and disease. OA Biochemistry1.

18. Fearnley GW, Smith GA, Abdul-Zani I, et al. (2016) VEGF-A isoforms program differential VEGFR2 signal transduction, trafficking, and proteolysis. Biol Open 5:571-583.

19. Smith GA, Fearnley GW, Harrison MA, Tomlinson DC, Wheatcroft SB, Ponnambalam S (2015) Vascular endothelial growth factors: Multitasking functionality in metabolism, health and disease. J Inherit Metab Dis. 38:753-763.

20. Hendel RC, Henry TD, Rocha-Singh K, et al. (2000) Effect of intracoronary recombinant human vascular endothelial growth factor on myocardial perfusion: Evidence for a dose-dependent effect. Circulation 101:118-121.

21. Eppler SM, Combs DL, Henry TD, et al. (2002) A targetmediated model to describe the pharmacokinetics and hemodynamic effects of recombinant human vascular endothelial growth factor in humans. Clin Pharmacol Ther. 72:20-32.

22. Leung DW, Cachianes G, Kuang WJ, Goeddel DV, Ferrara $\mathrm{N}$ (1989) Vascular endothelial growth factor is a secreted angiogenic mitogen. Science 246:1306-1309.

23. Gyongyosi M, Khorsand A, Zamini S, et al. (2005) NOGAguided analysis of regional myocardial perfusion abnormalities treated with intramyocardial injections of plasmid encoding vascular endothelial growth factor A-165 in patients with chronic 
myocardial ischemia: Subanalysis of the EUROINJECT-ONE multicenter double-blind randomized study. Circulation 112: I157-1165.

24. Stewart DJ, Kutryk MJ, Fitchett D, et al. (2009) VEGF gene therapy fails to improve perfusion of ischemic myocardium in patients with advanced coronary disease: Results of the NORTHERN trial. Mol Ther 17:1109-1115.

25. Hedman M, Hartikainen J, Syvanne M, et al. (2003) Safety and feasibility of catheter-based local intracoronary vascular endothelial growth factor gene transfer in the prevention of postangioplasty and in-stent restenosis and in the treatment of chronic myocardial ischemia: Phase II results of the Kuopio angiogenesis trial (KAT). Circulation. 107:2677-2683.

26. Kastrup J, Jorgensen E, Fuchs S, et al. (2011) A randomized, double-blind, placebo-controlled, multicentre study of the safety and efficacy of BIOBYPASS (AdGVVEGF121.10NH) gene therapy in patients with refractory advanced coronary artery disease: The NOVA trial. EuroIntervention 6:813-818.

27. Henry TD, Annex BH, McKendall GR, et al. (2003) The VIVA trial: Vascular endothelial growth factor in ischemia for vascular angiogenesis. Circulation 107:1359-1365.

28. Sato K, Wu T, Laham RJ, et al. (2001) Efficacy of intracoronary or intravenous VEGF165 in a pig model of chronic myocardial ischemia. J Am Coll Cardiol 37:616-623.

29. Henry TD, Rocha-Singh K, Isner JM, et al. (2001) Intracoronary administration of recombinant human vascular endothelial growth factor to patients with coronary artery disease. Am Heart J 142:872-880.

30. Halvorsen YC, Wilkison WO, Gimble JM (2000) Adiposederived stromal cells--their utility and potential in bone formation. Int J Obes Relat Metab Disord 24: 41-44.

31. Kapur SK, Dos-Anjos Vilaboa S, Llull R, Katz AJ (2015) Adipose tissue and stem/progenitor cells: Discovery and development. Clin Plast Surg 42:155-167.

32. Brown SA, Levi B, Lequeux C, Wong VW, Mojallal A, Longaker MT (2010) Basic science review on adipose tissue for clinicians. Plast Reconstr Surg 126:1936-1946.
33. De Francesco F, Ricci G, D'Andrea F, Nicoletti GF, Ferraro GA (2015) Human adipose stem cells: From bench to bedside. Tissue Eng Part B Rev 21:572-584.

34. Strem BM, Zhu M, Alfonso Z, et al. (2005) Expression of cardiomyocytic markers on adipose tissue-derived cells in a murine model of acute myocardial injury. Cytotherapy 7:282-291.

35. Lavoie JR, Rosu-Myles M (2013) Uncovering the secrets of mesenchymal stem cells. Biochimie 95:2212-2221.

36. Planat-Benard V, Silvestre JS, Cousin B, et al. (2004) Plasticity of human adipose lineage cells toward endothelial cells: Physiological and therapeutic perspectives. Circulation 109:656-663.

37. Fraser JK, Schreiber R, Strem B, et al. (2006) Plasticity of human adipose stem cells toward endothelial cells and cardiomyocytes. Nat Clin Pract Cardiovasc Med 3:33-37.

38. Taimeh Z, Loughran J, Birks EJ, Bolli R (2013) Vascular endothelial growth factor in heart failure. Nat Rev Cardiol 10:519530 .

39. Nakagami H, Maeda K, Morishita R, et al. (2005) Novel autologous cell therapy in ischemic limb disease through growth factor secretion by cultured adipose tissue-derived stromal cells. Arterioscler Thromb Vasc Biol. 25:2542-2547.

40. Goumans MJ, Zwijsen A, Ten Dijke P, Bailly S (2018) Bone morphogenetic proteins in vascular homeostasis and disease. Cold Spring Harb Perspect Biol 10:10.

41. Schultheiss TM, Burch JB, Lassar AB (1997) A role for bone morphogenetic proteins in the induction of cardiac myogenesis. Genes Dev 11:451-462.

42. Mohler ER,3rd, Gannon F, Reynolds C, Zimmerman R, Keane MG, Kaplan FS (2001) Bone formation and inflammation in cardiac valves. Circulation 103:1522-1528.

43. Duan X, Murata Y, Liu Y, Nicolae C, Olsen BR, Berendsen AD (2015) Vegfa regulates perichondrial vascularity and osteoblast differentiation in bone development. Development 142:1984-1991.

44. Street J, Lenehan B (2009) Vascular endothelial growth factor regulates osteoblast survival - evidence for an autocrine feedback mechanism. J Orthop Surg Res 4:19-799X-4-19.

45. Deckers MM, van Bezooijen RL, van der Horst G, et al. (2002) Bone morphogenetic proteins stimulate angiogenesis through osteoblast-derived vascular endothelial growth factor A. Endocrinology 143:1545-1553. 
46. Conn G, Bayne ML, Soderman DD, et al. (1990) Amino acid and cDNA sequences of a vascular endothelial cell mitogen that is homologous to platelet-derived growth factor. Proc Natl Acad Sci U S A 87:2628-2632.

Submit your manuscript to a JScholar journal and benefit from:

ฯ Convenient online submission

- Rigorous peer review

I Immediate publication on acceptance

- Open access: articles freely available online

I High visibility within the field

I Better discount for your subsequent articles

Submit your manuscript at http://www.jscholaronline.org/submit-manuscript.php 